\title{
Lifetime Prevalence of Cognitive Impairment by Chinese-Modified NIMH Diagnostic Interview Schedule Among the Elderly in Taiwan Communities
}

\author{
Eng-Kung Yeh \\ Hai-Gwo Hwu \\ Taipai City Psychiatric Center \\ National Taiwan University \\ and National Taiwan University \\ Ly-Yung Chang \\ Yuan-Lih Yeh \\ Institute of Ethnology, \\ Taipei City Psychiatric Center \\ Academia Sinica
}


and social problems concerned with the elderly. Estimation of the true figure of dementia, their demographic distribution, risk-factors, natural history and the needs for help etc. in community population have, therefore, become the subjects with increasing interest for study by epidemiologists, public health professionals and gerontologists.

The detection of dementia in community population in its early stage is very important, yet is, as Henderson and Huppert (1984), and Huppert and Tym (1986) pointed out, difficult. The urgent needs in detection of dementia in community population have stimulated efforts to establish case-finding tools which can be easily and reliably applied to reach the accurate clinical diagnosis in recent years. The NIMH Diagnostic Interview Schedule (DIS) was established specifically to satisfy these needs, and has been used as the case-finding tool in the NIMH Epidemiological Catchment Area (ECA) Program, a nation-wide collaborative project involving five university research centers in five study sites and the NIMH (Robins et al. 1981). The goal of the NIMH ECA program is to determine rates of incidence and prevalence of specific mental disorders, their risk-factors, demographic distributions, and to find the relationship between psychiatric disorders and the utilization of health and mental health services (Regier $e t$ al. 1984).

Briefly, the NIMH DIS is a set of highly structured questions with clearly defined criteria designed to reach the DSM-III diagnosis of major mental disorders through computer processing of the data obtained from interview. It elicits the elements of a diagnosis including symptoms, their severity, frequency, distribution over time, and whether or not they can be explained by physical illness, drug or alcohol use or another psychiatric diagnosis. Diagnosis can be generated both currently (last 2 weeks, 1 month, 6 months, 1 year) and over a lifetime. The DIS has been found to be reliably used by non-professionals after a short course of training, and has thus been claimed to be particularly useful as a case-finding method in the study of large population samples (Robins et al. 1981). Because of its unique value as a case-finding tool, it has been translated into German, Spanish, Chinese, and more recently in Japanese for application in epidemiological study of mental disorders in community population (Helzer 1985).

In order to obtain the up-to-date findings on incidence and prevalence of mental disorders, and the related data in community population, the Department of Health of the Executive Yuan (Cabinet) initiated a five-year nation-wide research project known as Taiwan Psychiatric Epidemiological Project (TPEP) in 1981 (Yeh and Hwu 1981-6). The Chinese Version of the NIMH DIS was the case-finding tool adopted in the TPEP. This paper reports some preliminary findings on prevalence of cognitive impairment obtained from the TPEP. 


\section{METHOD OF STUDY}

\section{Sampling Method}

The TPEP was designed to study the community population aged 18 years and over covering three different types of community; namely, urban, township and rural village. Taipei City was chosen to represent an urban community for the first segment of the TPEP. For the second segment of the TPEP, Su-lin and Tsau-tung were selected to represent two different subtypes of township in present day Taiwan. Su-lin is a town geographically near to Taipei City and has experienced a higher population mobility associated with industrialization in the past six years, but Tsau-tung is geographically isolated from the large city and has experienced a stable population mobility during the identical period of time. For the third segment of the TPEP, six countries (Hsiang), two each from the northern, central, and southern parts of Taiwan with a total of 90 villages (Tsuang) were drawn to represent three different subtypes of rural village in present day Taiwan, namely; the typical farming, fishing, and mixture of both. The multi-staged stratified sampling method was employed in each of the three study sites to draw the study samples which represented the general population members of the study sites aged 18 years and over. The detailed sampling method has been reported elsewhere (Chang $e t$ al. 1984). Altogether, 5000 samples drawn from Taipei City and 3000 each from two townships and six countries (Hsiang) were studied in the TPEP during 1982-5.

\section{Case-Identification Method}

The Chinese Version II of the NIMH Diagnostic Interview Schedule (DIS-CMII) was used in the study of Taipei City in 1982, the DIS-CM-III in the study of two townships in 1984, and the DIS-CM-IV in the study of villages in 1985. The development of the Chinese Versions of the NIMH DIS, its inter rater reliability, and validity of case-identification have been reported in details elsewhere (Hwu et al. 1983, 1984; Hwu et al. 1986; Hwu et al. 1986).

\section{Interviewing}

All interviewing was conducted in the field by trained interviewers. Fifty senior students of medicine, psychology and health education in the first study, and of medicine in the second and third studies, selected from 70-80 applicants, served as interviewers in all three parts of the TPEP after a carefully and comprehensively designed two-week full-time training course. The training program consisted of general orientation to the TPEP, didactic lectures, observation of videotaped interview with the DIS-CM, practice of interview with clinical and community samples, exercise in scoring with mutual analysis, and assigned homework. The 
inter rater reliability with the DIS-CM-II in the first study and with the DIS-CMIII in the 2 nd study, after the training, were highly satisfactory.

\section{Mini-Mental Status Examination (MMSE)}

Mini-Mental Status Examination (MMSE) developed by Folstein et al. (1975) was adopted in the NIMH DIS to assess cognitive impairment. The MMSE was developed to provide a short clinical screen for the presence of dementia or related disorders producing impairment of cognitive function. It is a simplified scored form of a cognitive mental status examination which includes 11 questions, and required only 10-15 minutes to administer. It concentrates on cognitive aspects of mental function and excludes questions concerning mood, abnormal mental experiences and for the form of thinking. The questions cover: orientation to time and place; memory; attention and calculation; follow verbal and written command; name shown objects; write a sentence; and copy a pair of pentagons. The total maximal score is 30 correct responses. The criteria for mild and severe cognitive impairment adopted in this study are based on the DIS-III Computer Diagnostic programs for the NIMH DIS Version III as shown in Table 1.

TABLE 1

Diagnostic Programs for Cognitive Impairment in NIMH Diagnostic Interview Schedule

\begin{tabular}{llcc}
\hline \multicolumn{3}{c}{ Version III } \\
\hline ORBRAIN & OBSTOT & TOTWRNG \\
\hline 1 Absent & $0-6$ & $0-6$ \\
2 Definitely mild & $7-12$ & $7-12$ \\
3 & Definitely severe & $13+$ & $13+$ \\
4 & Possibly severe, definitely mild & $7-12$ & $13+$ \\
6 & Possibly mild, may be absent & $0-6$ & $7-12$ \\
7 & Could be severe, mild or absent & $0-6$ & $13+$ \\
& Indeterminate & $0-4$ & $26+$ \\
\hline
\end{tabular}

OBSTOT: The total number of errors in the entire MMSE.

TOTWRNG: The sum of errors plus refusals, not ascertained, and missing in the entire MMSE. 


\section{RESULTS}

\section{Sociodemographic Findings}

The sociodemographic distributions of the study samples in four age-groups, and by educational levels, marital status, domicile of origin, and occupations are significantly different between each of the three study sites as shown in Table 2. This indicates the different sociodemographic composition of the inhabitants in Taipei City, two townships and rural villages in present day Taiwan, and illustrates the necessity of selecting population in each of the three areas in order to have a study sample that is representative of the full range of the Taiwan population. In order to make the prevalence rates comparable between each of the three study sites, the prevalence rates shown in this study are adjusted by sex and age-groups.

\section{Lifetime Prevalence by Sex and Age-groups.}

The lifetime prevalence of definitely mild, possibly severe, and definitely severe cognitive impairment in the population aged 65 and older $(2.8 \%, 1.6 \%, 1.3 \%$ in Taipei; $12.9 \%, 9.0 \%, 7.6 \%$ in township; $12.9 \%, 5.4 \%, 1.8 \%$ in rural) are all significantly higher than those of the population aged 64 and younger $(0.6 \%, 0.1 \%$, $0.04 \%$ in Taipei; $2.6 \%, 0.7 \%, 0.4 \%$ in township; $2.5 \%, 0.6 \%, 0.3 \%$ in rural) respectively, as shown in Table 3 . The lifetime prevalence of all three categories of cognitive impairment are significantly higher among the females than males in the population aged 64 and younger, while these findings are inconsistent in the population aged 65 and older in each of the three sites. For example, in Taipei City the prevalence of definitely mild and severe cognitive impairment are higher in females than males, the rate of possibly severe impairment are roughly the same between two sexes. In townships and rural villages, the higher female rates of cognitive impairment are observed in definitely mild, and possibly severe groups with roughly the same rates for the definitely severe groups between the two sexes.

\section{Lifetime Prevalence in Elderly Population}

As shown in Table 4, the prevalence of cognitive impairment in the population aged 65 and over increases with age, significantly in the groups with definitely severe cognitive impairment for both sexes, respectively, across the three sites. This finding is observed only in Taipei City, and not in the townships and rural villages for the prevalence of mild cognitive impairment. As shown in Table 5, the overall prevalence of cognitive impairment including definitely mild, possibly severe, and definitely severe categories increase with age among both sexes in Taipei and townships, respectively, while in rural villages the corresponding prevalences of cognitive impairment decrease on the contrary in the 75-84 age-group of both sexes, respectively. 
TABLE 2

Sociodemographic Data in Three Sites of the TPEP

\begin{tabular}{|c|c|c|c|}
\hline & & $\begin{array}{c}\text { Taipei } \\
N=500\end{array}$ & \\
\hline Sociodemographic Data & $\begin{array}{c}\text { Male } \\
\%\end{array}$ & $\begin{array}{c}\text { Female } \\
\%\end{array}$ & $\begin{array}{c}\text { Total } \\
\%\end{array}$ \\
\hline \multicolumn{4}{|l|}{ Age-group $* \dagger \ddagger$} \\
\hline $18-24$ years & 17.6 & 21.2 & 19.4 \\
\hline $25-44$ years & 42.1 & 49.6 & 45.8 \\
\hline 45-64 years & 31.5 & 22.8 & 27.1 \\
\hline $65+$ years & 8.8 & 6.6 & 7.7 \\
\hline \multicolumn{4}{|l|}{ Education $* \dagger \ddagger$} \\
\hline 9th grade and lower & 40.4 & 50.7 & 45.6 \\
\hline 10th grade and higher & 59.6 & 49.3 & 54.2 \\
\hline \multicolumn{4}{|l|}{ Marital status $\dagger$} \\
\hline Married & 68.4 & 69.9 & 69.1 \\
\hline Never married & 26.6 & 21.8 & 24.2 \\
\hline Others & 5.0 & 8.3 & 6.7 \\
\hline \multicolumn{4}{|l|}{ Domicile of Origin $* \dagger \ddagger$} \\
\hline Native Taiwanese & 62.3 & 73.9 & 68.2 \\
\hline Others & 37.7 & 26.1 & 31.8 \\
\hline \multicolumn{4}{|l|}{ Occupation $*+\ddagger$} \\
\hline I IV \& & 52.1 & 33.1 & 42.5 \\
\hline V-VII \& Others \& & 32.8 & 19.3 & 25.9 \\
\hline \multicolumn{4}{|c|}{ House-keeping, students and } \\
\hline
\end{tabular}

* Taipei vs Townships $p<0.05$

$\dagger$ Townships vs Rural p $<0.05$

\&ural vs Taipei $p<0.05$

$\$$ Professionals, executive of large or medium-sized enterprise, administrator, owner of store, clerical, sales or service worker

\$ Skilled worker, semi-skilled worker, non-skilled worker 
Table 2 continued

\begin{tabular}{|c|c|c|c|c|c|}
\hline & $\begin{array}{l}\text { Township } \\
N=3004\end{array}$ & & & $\begin{array}{c}\text { Rural } \\
\mathbf{N}=2995 \\
\end{array}$ & \\
\hline Male & Female & Total & Male & Female & Total \\
\hline 22.0 & 24.4 & 23.1 & 27.1 & 29.8 & 28.3 \\
\hline 49.5 & 46.6 & 48.1 & 39.8 & 38.0 & 39.0 \\
\hline 22.5 & 20.9 & 21.8 & 25.7 & 24.5 & 25.2 \\
\hline 6.0 & 8.1 & 7.0 & 7.3 & 7.7 & 7.5 \\
\hline 63.5 & 73.5 & 68.1 & 72.7 & 82.6 & 77.2 \\
\hline 36.5 & 26.5 & 31.9 & 27.3 & 17.4 & 22.8 \\
\hline 70.4 & 72.1 & 71.2 & 65.8 & 69.7 & 67.5 \\
\hline 26.2 & 18.3 & 22.4 & 30.1 & 20.8 & 25.9 \\
\hline 3.4 & 9.6 & 6.4 & 4.1 & 9.5 & 6.5 \\
\hline 92.2 & 94.3 & 93.2 & 96.4 & 97.9 & 97.1 \\
\hline 7.8 & 5.7 & 6.8 & 3.6 & 2.1 & 2.9 \\
\hline 29.3 & 18.1 & 24.0 & 16.2 & 10.7 & 13.7 \\
\hline 64.3 & 42.7 & 54.1 & 77.8 & 45.7 & 63.3 \\
\hline 6.4 & 39.2 & 21.9 & 6.0 & 43.6 & 23.0 \\
\hline
\end{tabular}


TABLE 3

Lifetime Prevalence of Cognitive Impairment in General Population Age $\leq 64$ and $\geq 65$ in Three Sites of Taiwan Community by Chinese-Modified NIMH Diagnostic Interview Schedule (Adjusted by Sex and Age)

\begin{tabular}{|c|c|c|c|c|c|c|}
\hline \multicolumn{7}{|c|}{ Taipei } \\
\hline & & \multicolumn{3}{|c|}{$\% \pm \mathrm{SE}$} & \multicolumn{2}{|c|}{$\begin{array}{l}\text { Size of } \\
\text { sample }\end{array}$} \\
\hline & & I & II & III & $\mathbf{N}$ & $\%$ \\
\hline \multirow{4}{*}{ Male } & $\leq 64$ & $0.3 \pm 0.1$ & 0 & 0 & 2249 & 91.2 \\
\hline & $\geq 65$ & $1.8 \pm 0.9$ & $0.5 \pm 0.5$ & $1.4 \pm 0.8$ & 217 & 8.8 \\
\hline & Total & $0.4 \pm 0.1$ & $0.03 \pm 0.04$ & $0.1 \pm 0.1$ & 2466 & 100.0 \\
\hline & $\leq 64$ & $0.9 \pm 0.2$ & $0.1 \pm 0.1$ & $0.3 \pm 0.1$ & 2370 & 93.3 \\
\hline \multirow[t]{8}{*}{ Female } & $\geq 65$ & $4.1 \pm 1.5$ & $2.4 \pm 1.2$ & $1.8 \pm 1.0$ & 169 & 6.7 \\
\hline & Total & $1.2 \pm 0.2$ & $0.3 \pm 0.1$ & $0.4 \pm 0.1$ & 2539 & 100.0 \\
\hline & $\leq 64$ & $0.6 \pm 0.1$ & $0.04 \pm 0.03$ & $0.1 \pm 0.1$ & 4619 & 92.2 \\
\hline & $\geq 65$ & $2.8 \pm 0.8$ & $1.3 \pm 0.6$ & $1.6 \pm 0.6$ & 386 & 7.8 \\
\hline & Total & $0.8 \pm 0.1$ & $0.1 \pm 0.1$ & $0.3 \pm 0.1$ & 5005 & 100.0 \\
\hline & & \multicolumn{3}{|c|}{ Township } & & \\
\hline & & \multicolumn{3}{|c|}{$\% \pm \mathrm{SE}$} & \multicolumn{2}{|c|}{$\begin{array}{l}\text { Size of } \\
\text { sample }\end{array}$} \\
\hline & & I & II & III & $\mathbf{N}$ & $\%$ \\
\hline \multirow{3}{*}{ Male } & $\leq 64$ & $1.7 \pm 0.3$ & $0.3 \pm 0.1$ & $0.4 \pm 0.2$ & 1484 & 94.0 \\
\hline & $\geq 65$ & $8.4 \pm 2.9$ & $7.4 \pm 2.7$ & $2.1 \pm 1.5$ & 95 & 6.0 \\
\hline & Total & $2.2 \pm 0.4$ & $0.8 \pm 0.2$ & $0.5 \pm 0.2$ & 1579 & 100.0 \\
\hline \multirow{6}{*}{ Female } & $\leq 64$ & $3.6 \pm 0.5$ & $0.6 \pm 0.2$ & $1.1 \pm 0.3$ & 1310 & 91.9 \\
\hline & $\geq 65$ & $16.5 \pm 3.5$ & $7.8 \pm 2.5$ & $14.8 \pm 3.3$ & 115 & 8.1 \\
\hline & Total & $4.6 \pm 0.6$ & $1.1 \pm 0.3$ & $2.2 \pm 0.4$ & 1425 & 100.0 \\
\hline & $\leq 64$ & $2.6 \pm 0.3$ & $0.4 \pm 0.1$ & $0.7 \pm 0.2$ & 2794 & 93.0 \\
\hline & $\geq 65$ & $12.0 \pm 2.3$ & $7.6 \pm 1.8$ & $9.0 \pm 2.0$ & 210 & 7.0 \\
\hline & Total & $3.3 \pm 0.3$ & $1.0 \pm 0.2$ & $1.3 \pm 0.2$ & 3004 & 100.0 \\
\hline
\end{tabular}




\begin{tabular}{|c|c|c|c|c|c|c|}
\hline & & & Rural & & & \\
\hline & & & $\% \pm \mathrm{SE}$ & & Size of & \\
\hline & & I & II & III & $\mathbf{N}$ & $\%$ \\
\hline & $\leq 64$ & $1.8 \pm 0.3$ & $0.2 \pm 0.1$ & $0.1 \pm 0.1$ & 1523 & 92.7 \\
\hline Male & $\geq 65$ & $8.3 \pm 2.5$ & $1.7 \pm 1.2$ & $0.8 \pm 0.8$ & 120 & 7.3 \\
\hline & Total & $2.3 \pm 0.4$ & $0.3 \pm 0.1$ & $0.2 \pm 0.1$ & 1643 & 100.0 \\
\hline & $\leq 64$ & $3.3 \pm 0.5$ & $0.4 \pm 0.2$ & $1.1 \pm 0.3$ & 1248 & 92.3 \\
\hline Female & $\geq 65$ & $18.3 \pm 3.8$ & $1.9 \pm 1.4$ & $10.6 \pm 3.0$ & 104 & 7.7 \\
\hline & Total & $4.4 \pm 0.6$ & $0.5 \pm 0.2$ & $1.6 \pm 0.4$ & 1352 & 100.0 \\
\hline & $\leq 64$ & $2.5 \pm 0.3$ & $0.3 \pm 0.1$ & $0.6 \pm 0.1$ & 2771 & 92.5 \\
\hline & $\geq 65$ & $12.9 \pm 2.2$ & $1.8 \pm 0.9$ & $5.4 \pm 1.5$ & 224 & 7.5 \\
\hline & Total & $3.3 \pm 0.3$ & $0.4 \pm 0.1$ & $0.9 \pm 0.2$ & 2995 & 100.0 \\
\hline
\end{tabular}

1 Definitely mild

II Definitely severe

III Definitely mild, possibly severe

\section{Inter-sites Comparison}

As shown in Table 6, the overall lifetime prevalence of cognitive impairment including the three categories of severity in population aged 65 and over is highest in township (29.5\%), next highest in rural (20.1\%), and lowest in Taipei (5.7\%) with significant differences among the three sites. The differences between township and rural are, however, not significant when the prevalence of mild cognitive impairment, and the overall prevalence including both mild and severe in each of sex groups are compared.

The prevalence in each category of cognitive impairment between the three sites are, as shown in Table 4, inconsistent. The rates of mild impairment in townshipand rural are reasonably the same, and both are significantly higher than that of Taipei. The rate of definitely severe impairment is significantly higher in township than in both Taipei and rural, with reasonably the same rates between the latter two sites. The rates for the group with possibly severe impairment is highest in township and lowest in Taipei with rural standing in between. 


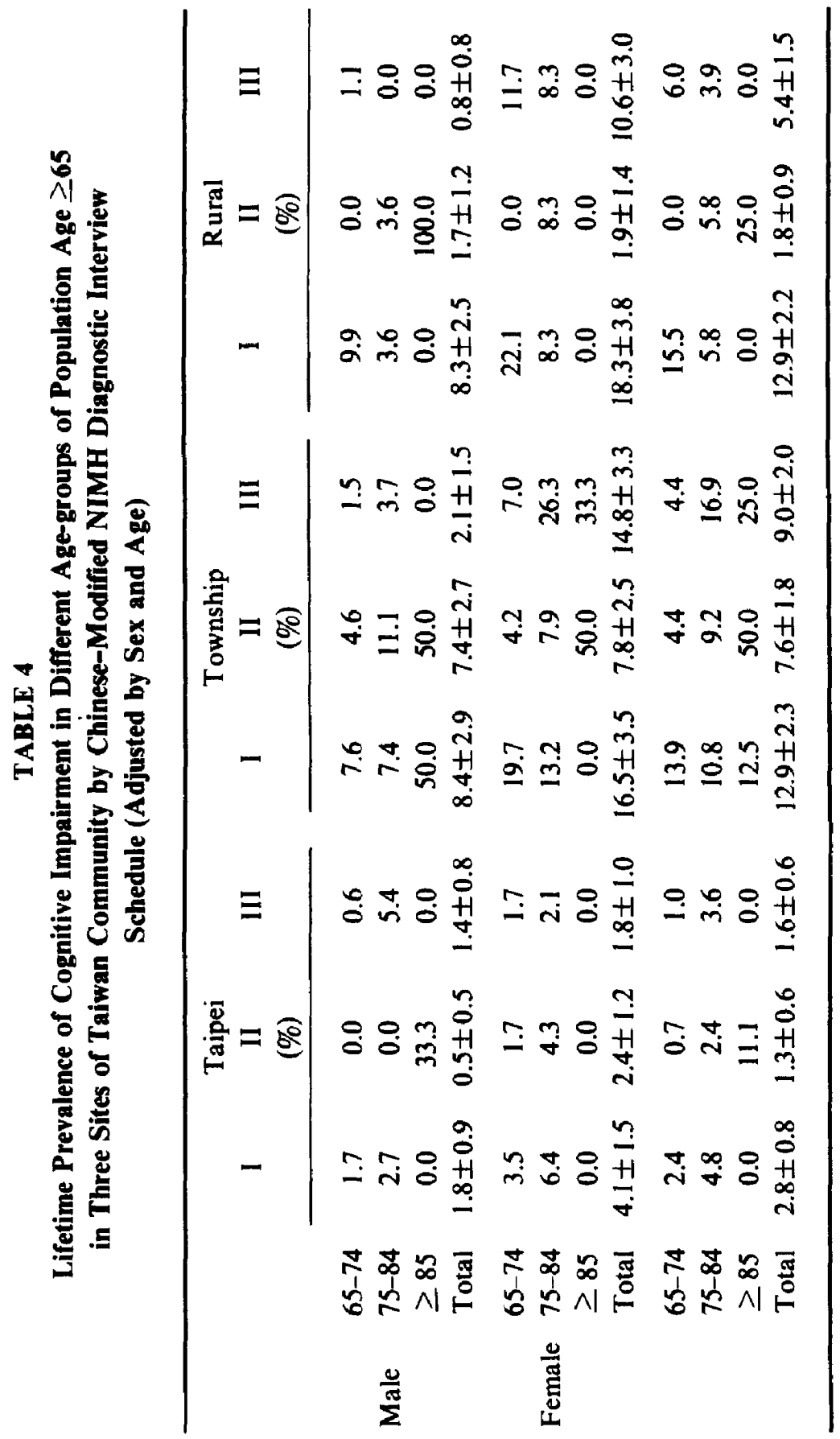




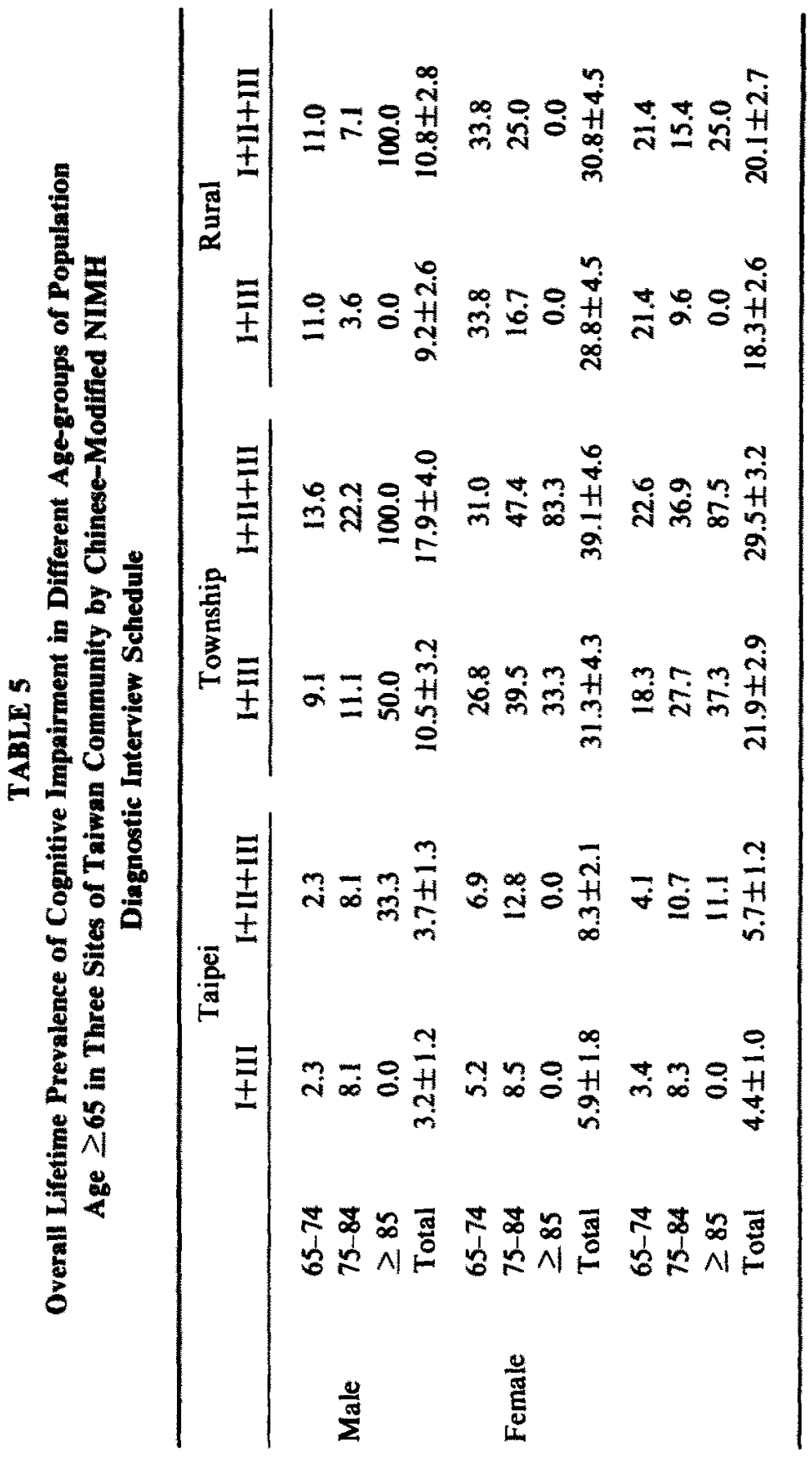




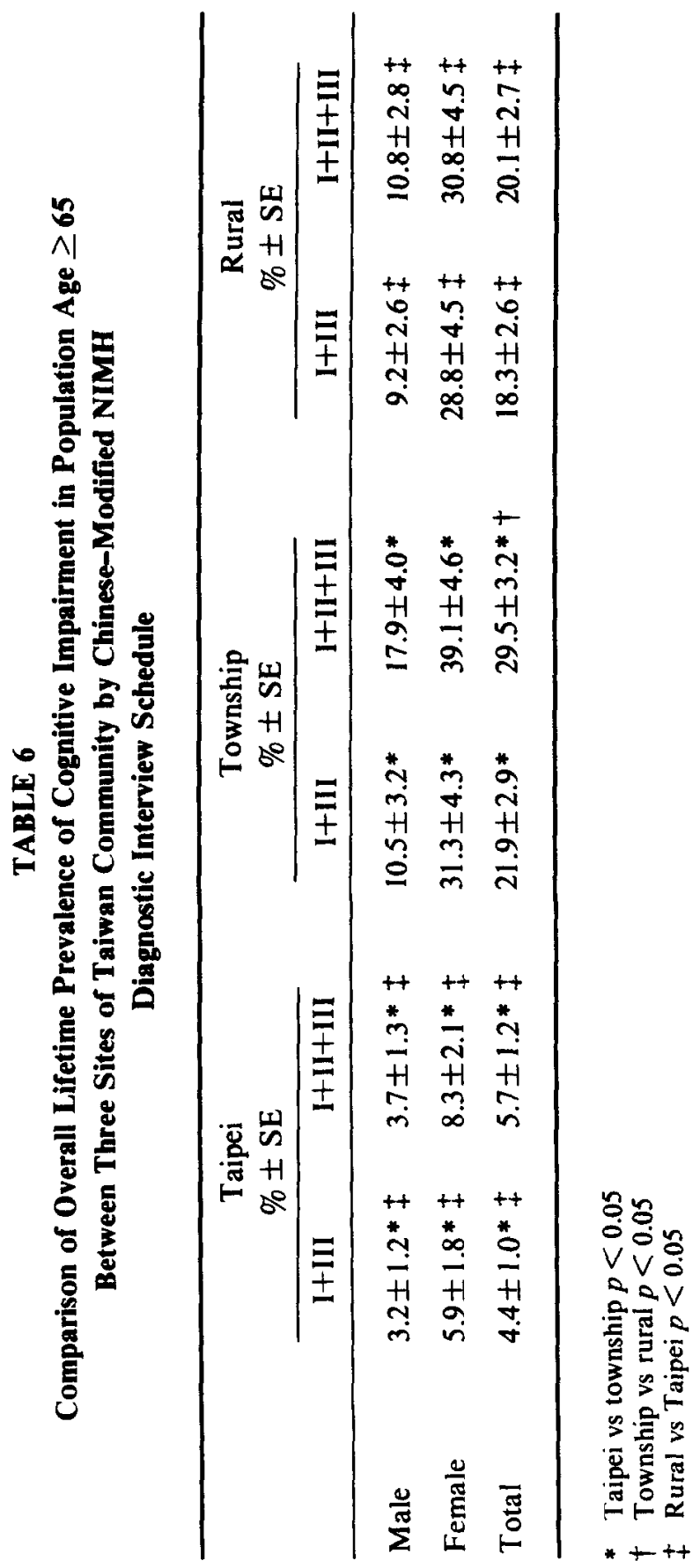


The differences in prevalence of cognitive impairment between males and females in the elderly population in each of the three sites are inconsistent as shown in Table 4. In Taipei and rural, the rates for the groups with definitely mild and severe are higher in 65-74 and 75-84 age-groups of females than males, while these findings are observed only in two mildly impaired groups (I and III) and not in a definitely severe group. On the contrary, the rates with definitely severe impairment in the aged 85 and over group are higher in males than females in Taipei and rural, but the rates are the same between the two sexes in townships. The rates for the group with definitely mild and possibly severe impairment are higher in all three agegroups of females in township and rural, while these findings are observed only in the 65-74 age group in Taipei where the rates are higher among the males for the $75-84$ age group.

\section{Symptom Profile}

As shown in Tables 7 and 8, the mean number of errors and refusals in the questions regarding "orientation to time and place," "memory," "attention and calculation," and "follow verbal command" and "name shown objects" among the cases do not show significant differences between each of the three sites, except the higher rates of refusal in township than rural for the question regarding "orientation to time," while the rates of errors in the other three questions regarding "follow written command," "write a sentence" and "copy a pair of pentagons" show consistent and significant differences in cases between each of the three sites. The cases both in Taipei and township show higher impairment rates in "follow written command," "write a sentence" and "copy a pair of pentagons" than those in rural with no significant difference between the former two sites. While the rates of errors among the non-cases show some significant but inconsistent differences between the three sites. The elderly non-cases in township show more impaired "orientation to time and to place," and "memory" than those in Taipei and rural, and in "copy a pair of pentagons" than those in Taipei, while those in rural show more impairment in "attention and calculation," "follow verbal command" and "name shown objects" than those in Taipei and township, and more impaired function in "copy a pair of pentagons" than those in Taipei.

The attitudes of the elderly towards the MMSE as indicated by the mean number and/or proportion of refusals to respective questions is highly interesting. The elderly in rural refuse more often the questions regarding "orientation to time and place," "memory," "attention and calculation" and "copy a pair of pentagons" than those in Taipei and township, while those in Taipei show significantly more refusal rates to the questions regarding "follow written command" and "write a sentence" than those in township and rural; and to the question "copy a pair of pentagons" 


\section{TABLE 7}

Mean Number of Symptoms in Cases with Cognitive Impairment and Non-cases in Population Age $\geq 65$ in Three Sites of Taipei Community by Chinese-Modified NIMH Diagnostic Interview Schedule

\begin{tabular}{|c|c|c|c|c|}
\hline & \multicolumn{4}{|c|}{ Taipei $(\mathbf{M} \pm \mathrm{SD})$} \\
\hline & \multicolumn{2}{|c|}{ Case } & \multicolumn{2}{|c|}{ Non-case } \\
\hline & Error & Refusal & Error & Refusal \\
\hline Orientation to time & $2.5 \pm 1.8$ & $0.2 \pm 1.1$ & $0.3 \pm 0.7 *$ & $0.5 \pm 1.4$ \\
\hline Orientation to place & $1.4 \pm 1.9$ & $0.1 \pm 0.3$ & $0.1 \pm 0.4^{*}$ & $0.2 \pm 0.9$ \\
\hline Memory & $4.9 \pm 2.4$ & $0.4 \pm 0.5$ & $1.3 \pm 1.6 *$ & $0.8 \pm 1.4$ \\
\hline Calculation & $1.0 \pm 1.5$ & $2.5 \pm 2.3$ & $0.3 \pm 0.7 *$ & $1.4 \pm 2.1$ \\
\hline \multirow{4}{*}{$\begin{array}{c}\text { Follow verbal } \\
\text { command }\end{array}$} & $0.4 \pm 1.0$ & 0 & $0.1 \pm 0.1$ & $0.1 \pm 0.6$ \\
\hline & \multicolumn{4}{|c|}{ Township $(\mathbf{M} \pm \mathrm{SD})$} \\
\hline & \multicolumn{2}{|c|}{ Case } & \multicolumn{2}{|c|}{ Non-case } \\
\hline & Error & Refusal & Error & Refusal \\
\hline Orientation to time & $2.8 \pm 1.7$ & $0.1 \pm 0.6+$ & $0.5 \pm 0.9$ & $0.4 \pm 1.3 \dagger$ \\
\hline Orientation to place & $2.1 \pm 1.8$ & $0.1 \pm 0.6$ & $0.2 \pm 0.4 \dagger$ & $0.3 \pm 1.0 \dagger$ \\
\hline Memory & $4.9 \pm 3.2$ & $0.6 \pm 0.9$ & $1.9 \pm 1.8 \dagger$ & $0.7 \pm 1.1 \dagger$ \\
\hline Calculation & $0.6 \pm 1.4$ & $3.3 \pm 2.2$ & $0.5 \pm 1.0$ & $1.7 \pm 2.2$ \\
\hline $\begin{array}{c}\text { Follow verbal } \\
\text { command }\end{array}$ & $0.7 \pm 1.1$ & $0.0 \pm 0.4$ & $0.1 \pm 0.4 †$ & $0.1 \pm 0.5$ \\
\hline
\end{tabular}

\begin{tabular}{|c|c|c|c|c|}
\hline & \multicolumn{4}{|c|}{ Rural $(M \pm S D)$} \\
\hline & \multicolumn{2}{|c|}{ Case } & \multicolumn{2}{|c|}{ Non-case } \\
\hline & Error & Refusal & Error & Refusal \\
\hline Orientation to time & $2.6 \pm 1.5$ & $0.5 \pm 1.4$ & $0.5 \pm 0.9 \ddagger$ & $1.2 \pm 1.8 \ddagger$ \\
\hline Orientation to place & $1.5 \pm 1.8$ & $0.2 \pm 0.8$ & $0.1 \pm 0.4$ & $0.7 \pm 1.3 \ddagger$ \\
\hline Memory & $4.5 \pm 3.1$ & $0.7 \pm 0.9$ & $1.5 \pm 1.8$ & $1.2 \pm 1.6 \pm$ \\
\hline Calculation & $1.0 \pm 1.8$ & $3.4 \pm 2.3$ & $0.7 \pm 1.1 t$ & $2.2 \pm 2.4 \pm$ \\
\hline $\begin{array}{l}\text { Follow verbal } \\
\text { command }\end{array}$ & $0.6 \pm 0.9$ & 0 & $0.3 \pm 0.6 \pm$ & $0.1 \pm 0.6$ \\
\hline
\end{tabular}

* Taipei vs township $p<0.05$

+ Township vs rural $p<0.05$

I Rural vs Taipei $p<0.05$ 
than those in township. Generally, the refusal rates are lowest both among the cases and non-cases in township. The unusually high refusal rates in questions regarding "follow written command" and "write a sentence" among the cases and non-cases in Taipei, and in the questions "copy a pair of pentagons" among the cases and noncases in Taipei and rural, are noteworthy. These findings seem to suggest the limitation of the MMSE as a case-finding tool in study of cognitive impairment among the elderly in community population, and may in part explain the lower overall rates of cognitive impairment in Taipei than would be expected comparing with those in township and rural villages.

\section{DISCUSSION}

In any given current period of time, dementia among the elderly is perhaps the only disorder with higher prevalence rate which increases with age than that of the younger population.

The reported results of studies on prevalence of dementia in community population have yielded a rather consistent rate of around 5\% for the moderate and severe dementia (Henderson 1983) while the rates reported on mild dementia have varied from 2.6\% (Bergman et al. 1971) to 21.9\% (Parsons 1965). Kaneko (1969, 1975) even reported an unusually high rate of $52.7 \%$ in a community sample of 531 persons aged 65 and over in Japan. Studies with rates between these extremes have been reported by Essen-Moller (1956), Nielson (1962), Kay et al. (1964), Williamson (1964) and Helgason (1964). The results of these studies have indicated the importance and urgent needs in development of a set(s) of diagnostic schedule which can be easily and reliably used even by non-professionals after a short-term training in the study of large community population across cultures.

Though DSM-1II is an important break-through in psychiatric diagnosis, the criteria for dementia have been criticized (Jorm and Handerson 1985) for treating dementia categorically rather than dimentionally, ignoring the problems of placing appropriate cut-off and being too broad, thus, encouraging diagnostic unreliability. The MMSE was integrated in the NIMH DIS in an effort to supplement the criteria for serverity of impairment in DSM-III dementia. In a recent Australian study, Kay et al. (1985), however, found the MMES ineffective in detecting mild dementia and recommended the Pheffer (1981) Mental Function Index (MFI) which is the addition of the Smith Symbol Digit Design Test and the Raven's Metrices Subtest B to the MMES.

This is the very first study of cognitive impairment using the MMES on a large community population in Taiwan. Though the inter rater reliability of the interviewers were found to be satisfactorily high before field work in each segment of the TPEP, there was no way of testing the reliability of the inter-site interview data. The 
TABLE 8

Percentage of Symptoms in Cases with Cognitive Impairment and Non-cases in Population Age over $\geq 65$ in Three Sites of Taiwan Community by Chinese NIMH Diagnostic Interview Schedule

\begin{tabular}{lccccc}
\hline & \multicolumn{4}{c}{ Taipei (\%) } \\
& \multicolumn{2}{c}{ Case } & & \multicolumn{2}{c}{ Non-case } \\
\cline { 2 - 3 } \cline { 5 - 6 } & Error & Refusal & & Error & Refusal \\
\hline Name shown object (1) & 4.6 & 0 & & 0.3 & 2.5 \\
Name shown object (2) & 4.6 & 0 & & 0 & 2.2 \\
Follow written command & 31.8 & $40.9 *$ & & 3.5 & $27.5 *$ \\
Write a sentence & 50.0 & $31.8^{*}$ & & 6.3 & $34.1^{*}$ \\
Copy a pair of pentagons & 59.1 & $18.2^{*}$ & & $7.4^{*}$ & $22.6 *$ \\
\hline
\end{tabular}

Township (\%)

\begin{tabular}{lccccc} 
& \multicolumn{2}{c}{ Case } & & \multicolumn{2}{c}{ Non-case } \\
\cline { 2 - 3 } \cline { 5 - 6 } & Error & Refusal & & Error & Refusal \\
\hline Name shown object (1) & 9.7 & 0 & & 0.7 & 2.0 \\
Name shown object (2) & 9.7 & 0 & & 0.7 & 2.0 \\
Follow written command & $29.0 \dagger$ & 0 & & $6.1 \dagger$ & 3.4 \\
Write a sentence & $37.1 \dagger$ & 0 & & $10.1 \dagger$ & 7.4 \\
Copy a pair of pentagons & $56.5 \dagger$ & $4.8 \dagger$ & & 24.3 & $13.5 \dagger$ \\
& & & & & \\
\hline
\end{tabular}

\begin{tabular}{lccccc} 
& \multicolumn{4}{c}{ Rural (\%) } \\
\cline { 2 - 3 } \cline { 5 - 6 } Error & Error & Refusal & & Error & Refusal \\
\hline Name shown object (1) & 2.2 & 0 & & 0.6 & 1.1 \\
Name shown object (2) & 2.2 & 0 & & $1.1 \ddagger$ & 1.1 \\
Follow written command & $6.7 \ddagger$ & $0 \ddagger$ & & 1.1 & $6.2 \ddagger$ \\
Write a sentence & $4.4 \ddagger$ & $4.4 \ddagger$ & & 3.4 & $10.6 \ddagger$ \\
Copy a pair of pentagons & $33.3 \ddagger$ & 33.3 & & $20.7 \ddagger$ & $36.3 \ddagger$ \\
\hline
\end{tabular}

\footnotetext{
* Taipei vs township $p<0.05$

+ Township vs rural $p<0.05$

$\mp$ Rural vs Taipei $p<0.05$
} 
interviewers, before interviewing in each segment of the study were, however, trained by the same investigators with exactly the same teaching materials and schedule. Thus, theoretically, the inter-site reliability of interview data can be expected to be satisfactory. In view of the unusually high refusal rate to the questions "follow written command" and "write a sentence" in Taipei samples, the significantly lower rate of cognitive impairment among the elderly population in Taipei may partly be explained by defensive attitudes of the responders to this study, rather than by the bias in interviewing technique and rating of the data. The comparison of lifetime prevalence of cognitive impairment in general population aged 18 and over between the NIMH ECA sites and the TPEP, as shown in Table 9, seems to be in support of this speculation. The lower rate of cognitive impairment in urban than in rural is also supported by the two recent studies conducted in Taiwan, as shown in Table 9. Lin et al. (1984) and Rin (1987) used a two-stage case-finding method consisting of screening by non-medical interviewers with specifically designed interview schedule in the first stage and clinical examinations of the suspected cases in the second stage, and found $2.7 \%$ of clinically diagnosable dementia in rural area in southern Taiwan and $1.7 \%$ in Taipei, respectively. The cases of clinically diagnosable dementia that were screened out from the first stage interview in the above two studies are presumably equivalent to the definitely severe cases as defined in our study. The lower prevalence rate of cognitive impairment in the general population of urban than in rural is also seen in the NIMH ECA studies as shown in Table 10 (Blazer et al. 1985).

That the prevalence of overall as well as each category of cognitive impairment in townships are significantly higher than those in Taipei and rural is difficult to explain, and deserves further study.

Comparison of the TPEP findings with those of the NIMH ECA program shows that the prevalence rate of definitely severe cases both in Taipei and rural is significantly lower, and that in townships is seemingly higher than that in each of the NIMH ECA sites, as shown in Table 11 (Robins et al. 1984). Again, whether these findings are due to under-detection of the cases in Taipei and rural sites of the TPEP, or these are representing the true figures, need further study.

The rates of mild cognitive impairment are all higher among the females than males across the three sites of the Taiwan community, while the six-month prevalence for this group of cases is roughly the same in the three sites of NIMH ECA program, as shown in Table 12 (Weissman et al. 1985). The differences in prevalence of severe cognitive impairment between both sexes in the two countries are inconsistent. These seem to indicate the different vulnerability to dementia and the related disorders which caused cognitive impairment, and the survival rate between males and females in each of these two countries. 
TABLE 9

Prevalence of Dementia in Different Populations of Taiwan

\begin{tabular}{clllc}
\hline Investigator & $\begin{array}{l}\text { Type of } \\
\text { community }\end{array}$ & $\begin{array}{l}\text { Size of } \\
\text { population } \\
\text { studied }\end{array}$ & $\begin{array}{l}\text { Method of case } \\
\text { identification }\end{array}$ & $\begin{array}{c}\text { Prevalence } \\
\%\end{array}$ \\
\hline $\begin{array}{c}\text { Lin } \text { et al. } \\
1984\end{array}$ & Rural & 1023 & $\begin{array}{c}\text { Screening and clinical } \\
\text { diagnosis }\end{array}$ & 2.7 \\
Rin 1987 & Urban & 1586 & $\begin{array}{l}\text { Screening and clinical } \\
\text { diagnosis }\end{array}$ & 1.7 \\
$\begin{array}{r}\text { Lin } \text { et al. } \\
1981-2\end{array}$ & $\begin{array}{c}\text { Homes for } \\
\text { elderly }\end{array}$ & 1400 & $\begin{array}{c}\text { Screening and clinical } \\
\text { diagnosis }\end{array}$ & 7.4 \\
\hline
\end{tabular}

TABLE 10

Cross-cultural Comparison of Lifetime Prevalence of Cognitive Impairment (Severe) in Population Age $\geq 18$ by NIMH Diagnostic Interview Schedule

\begin{tabular}{cccccccc}
\hline \multicolumn{2}{c}{ NOMH ECA Sites } & & & \multicolumn{3}{c}{ TPEP } \\
\hline $\begin{array}{c}\text { New } \\
\text { Haven }\end{array}$ & $\begin{array}{c}\text { Balti- } \\
\text { more }\end{array}$ & $\begin{array}{c}\text { St } \\
\%\end{array}$ & $\begin{array}{c}\text { Louis } \\
\%\end{array}$ & $\begin{array}{c}\text { Durham } \\
\text { (Six-month) }\end{array}$ & Taipei & $\begin{array}{c}\text { Town- } \\
\text { ship }\end{array}$ & Rural \\
1.3 & 1.3 & 1.0 & $\begin{array}{c}\text { Urban } \\
1.2\end{array}$ & $\begin{array}{c}\text { Rural } \\
2.1\end{array}$ & $\%$ & $\%$ & $\%$ \\
\hline
\end{tabular}

* Including definitely and possibly severe cases

TABLE 11

Cross-cultural Comparison of Lifetime Prevalence of Cognitive Impairment (Severe) in Population Age $\geq \mathbf{6 5}$ by NIMH Diagnostic Interview Schedule

\begin{tabular}{cccccc}
\hline \multicolumn{3}{c}{ NIMH ECA Sites } & \multicolumn{3}{c}{ TPEP } \\
\hline New Haven & Baltimore & St Louis & Taipei & Township & Rural \\
$\%$ & $\%$ & $\%$ & $\%$ & $\%$ & $\%$ \\
5.0 & 5.1 & 4.0 & 1.3 & 7.6 & 1.8 \\
\hline
\end{tabular}




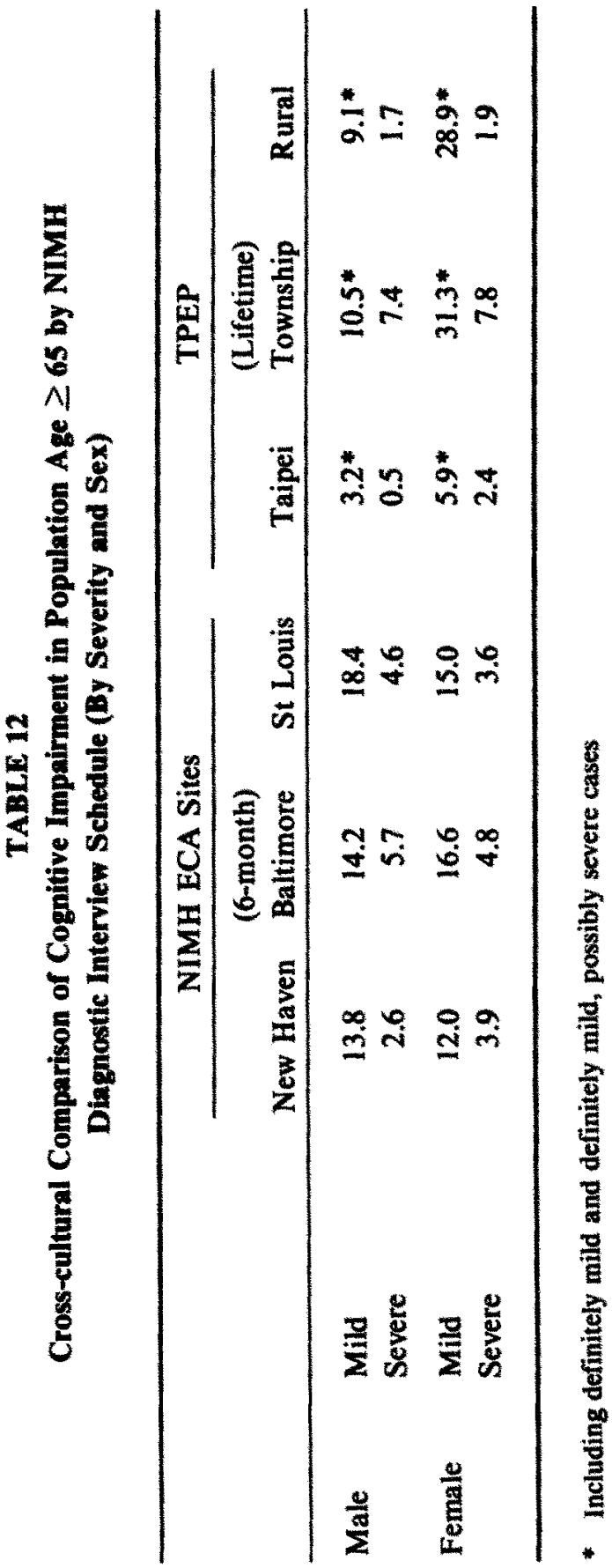




\section{ACKNOWLEDGEMENT}

This study was fully supported by the special funding from the Department of Health of the Executive Yuan, Republic of China.

\section{REFERENCES}

Henderson, A.S. and F. A. Huppert

1984 "The problem of mild dementia," Psychological Medicine 14. 5-11. Huppert, F. A. and E. Tym

1986 "Clinical and neurophysiological assessment of dementia," British Medical Bulletin 42. 11-8.

Robins, L. N., J.E. Helzer, J. Croughan, J.B.W. Williams and R. L. Spitzer

1981 "The NIMH Diagnostic Interview Schedule. Version III," Public Health Service (HSS), Publication ADM-T-42-3 (5-81, 8-81).

Robins, L. N., J.E. Helzer, J. Croughan and K.S. Ratcliff

1981 "The NIMH Diagnostic Interview Schedule: Its history, characteristics, and validity," Archives of General Psychiatry 38. 381-9.

Regier, D. A., J. K. Myers, M. Kramer, L.N. Robins, D. G. Blazer, R. L. Hough, W.W. Eaton and B.Z. Locke

1984 "The NIMH Epidemiologic Catchment Area Program: Historical context, major objectives, and study population characteristics," Archives of General Psychiatry 41. 934-41.

Helzer, J.E.

1985 "Cross-cultural application of the DIS," DIS Newsletter, Washington University School of Medicine, Department of Psychiatry. II-2. 3-4.

Yeh, E.K. and H.G. Hwu

1981- "Taiwan Psychiatric Epidemiological Study Project," Department of 1986 Health, Executive Yuan, Republic of China.

Chang, L.Y., E.K. Yeh and H.G. Hwu

1984 "Taipei Psychiatric Epidemiological Study: A Methodological note," Paper presented at Symposium on Cross-cultural Psychiatric Epidemiology, 11-12 May, Hong-Kong.

Hwu, H.G., E. K. Yeh, C.T. Chen, C.C. Chen and T.Y. Chen

1983 "An applicability of the Chinese Modification of Diagnostic Interview Schedule (DIS-CM)," Bulletin of Chinese Society of Neurology and Psychiatry 9. 30-8.

Hwu, H.G., E. K. Yeh, L.Y. Chang, C.C. Chen and T.Y. Chen

1984 "The Chinese Modification of NIMH Diagnostic Interview Schedule- 
Reliability Study on assessment of psychiatric symptoms," Psychology Testing 31. 15-26.

Hwu, H.G., E.K. Yeh and L.Y. Chang

1986 "Chinese Diagnostic Interview Schedule I. Agreement with physician's diagnosis," Acta Psychiatrica Scandinavica 73. 225-33.

Hwu, H.G., E.K. Yeh, L.Y. Chang and Y.L. Yeh

1986 "Chinese Diagnostic Interview Schedule Il. A validity study on estimation of lifetime prevalence," Acta Psychiatrica Scandinavica 73. 348-57.

Folstein, M.F., S.E. Folstein and P.R. McHugh

1975 "Mini Mental State: A practical method for grading the cognitive state of patients for clinicians," Journal of Psychiatric Research 189-98.

Henderson, A.S.

1983 "The coming epidemic of dementia," Australian and New Zealand Journal of Psychiatry 17. 117-27.

Bergman, K., D.W.K. Kay, E. M. Foster, A. A. Mckechnie and M. Roth

1971 "A follow-up study of randomly selected community residents to assess the effects of chronic brain syndrome and cerebrovascular disease," in New Prospects in the Study of Mental Disorders in Old Age, pp.856-65. Proceedings of the Vth World Congress of Psychiatry. Mexico. Excerpta Medica, Amsterdam.

Parsons, P.L.

1965 "Mental health in Swansea's old folk," British Journal of Preventive and Social Medicine 19. 43-7.

Kaneko, $\mathbf{Z}$.

1969 "Epidemiological studies on mental disorders of the aged in Japan," in Proceedings of the 8th International Congress of Gerontology, Vol. I, Abstracts of Symposia and Lectures, pp.284-87, Washington, DC: International Association of Gerontology.

Kaneko, $\mathbf{Z}$.

1975 "Care in Japan," in Modern Perspectives in the Psychiatry of Old Age, pp.514-30, J.G. Howells (ed.), New York: Burner/Mazel.

Essen-Möller, E.

1960 Individual traits and morbidity in Swedish rural population," Acta Psychiatrica Scandinavica Supplement 100.

Nielsen, $\mathrm{J}$.

1962 "Geronto-psychiatric period-prevalence investigation in a geographically delimited population," Acta Psychiatrica Scandinavica 38. 307-30.

Kay, D. W.K., P. Beamish and M. Roth

1964 "Old age mental disorders in Newcastle-upon-Tyne: I. A Study of 
Prevalence," British Journal of Psychiatry 110. 146-8.

Williamson, J., I.H. Stockoe, S. Gray, M. Fisher, A. Smith, A. McGhee and E. Stephenson

1964 “Old people at home: Their unreported needs," Lancet 1. 1117-20. Helgason, $T$.

1964 "Epidemiology of mental disorders in Iceland," Acta Psychiatrica Scandinavica 40. Supplement 173. 1-258.

Kay, D.W.K., A.S. Henderson, R. Scott, J. Wilson, D. Richwood and D. A. Grayson

1985 "Dementia and depression among the elderly living in the Hobart community: The effect of the diagnostic criteria on prevalence rates," Psychological Medicine 15. 771-88.

Pheffer, R. I., T. T. Kurosaki, C. H. J. Harrosh, J.M. Chance and D. Bates

1981 "A survey diagnostic tool for senile dementia," American Journal of Epidemiology 114. 515-27.

Lin, H.N., M.T. Tsai and H. Rin

1984 "Psychiatric disorders among old people in rural area," Bulletin Chinese Society of Neurology and Psychiatry 10: Special Issue, Psychogeriatric Studies, 1. 65-78.

Rin, $\mathbf{H}$.

n.d. "Problems and crisis of the family with demented elderly," Unpublished Manuscript.

Blazer, D., K. G. Linda, R. Landerman, P. Margaret, M.L. Mellville, M. Woodbury, K. G. Manton, K. Jordan and B. Lucke

1985 "Psychiatric disorder a rural/urban comparison," Archives of General Psychiatry 42. 651-6.

Robins, L.N., J.E. Helzer, M.M. Weissman, H. Orvaschel, E. Gruenberg, J.D. Burke and D.A. Regier

1984 "Lifetime prevalence of specific psychiatric disorders in Three Sites," Archives of General Psychiatry 41. 949-58.

Weissman, M.M., J.K. Myers, G.L. Tischler, C.E. Holzer, III, P. L. Leaf, H. Orvaschel and J. A. Brody

1985 "Psychiatric disorders (DSM-III) and cognitive impairment among the elderly in a U.S. urban community," Acta Psychiatrica Scandinavica 71. 366-79. 